Brit. J. industr. Med., 1962, 19, 151.

\title{
THE ASSESSMENT OF THE THERMAL ENVIRONMENT A REVIEW
}

\author{
BY \\ R. K. MACPHERSON \\ From the School of Public Health and Tropical Medicine, The University of Sydney, Sydney, Australia
}

(RECEIVED FOR PUBLICATION APRIL 24, 1962)

\begin{abstract}
The development of methods for the assessment of the thermal environment is traced, and the reasons for the devising of special indices of thermal stress are discussed. The more important of the indices are described, and it is shown that they conform to a restricted number of types. The general trend in their evolution is indicated and some guidance is given in their use.
\end{abstract}

The assessment of the thermal environment must be one of the oldest judgments made by man, and its antiquity has conferred upon it considerable respectability. Comment on the prevailing weather is an acceptable opening for any polite conversation, and it is interesting to observe that such comment is often accompanied by comparison-the day is warmer or cooler than the day before, or it is warm or cool for the time of year, and so on.

The antiquity of such assessments and their comparative evaluation contrasts strongly with the relative modernity of the ability to attribute numerical values to prevailing environmental conditions. The means to do this were entirely wanting until the beginning of the seventeenth century, when the first and most primitive type of air thermometer was introduced, by Galileo it is said, and another hundred years went by before Fahrenheit, about the year 1714, devised the first satisfactory thermometric scale. With the introduction of the Centigrade scale by Celsius some thirty years later, the science of thermometry can be considered to be firmly established.

The provision of a convenient and portable instrument for the measurement of air temperature, coinciding as it did with a period of exploration and colonization, led to a wide interest in the range of temperature occurring not in England and on the continent of Europe alone, but the world over. This interest in environmental temperature drew attention to the fact that other factors besides temperature determine the stress of the environment. For example, Ellis (1758), whilst reporting temperatures in Georgia around the century mark, goes on to say, "This same thermometer I have had in the equatorial parts of Africa . . . at Jamaica, and the West Indian Islands, and on examination of my journals I did not find that the quicksilver ever rose above the 87 and to that but seldom. And yet I think that $I$ have felt those degrees with moist air more disagreeable than what I now feel". The differing physiological effects of moist and dry air were also demonstrated in the laboratory about this time in the hot-room experiments of Blagden and Fordyce (Blagden, 1775a, b).

The realization of the importance of humidity was presumably the stimulus which led to the attempts to devise an instrument for the measuring of moisture in the air by Baumé, de Saussure and others (de Saussure's 'Essai sur l'hygrométrie' appeared in 1783), but the problem of hygrometry proved even more intractable than that of thermometry and was only established on a firm basis by the work of Ivory, August, Apjohn, Belli, and Regnault, in the first half of the nineteenth century. Those who are interested will find much of historical value in Shaw's paper to the Royal Society on hygrometric methods (Shaw, 1888), and a modern, though much briefer, evaluation of them in the recent work of Wexler and Brombacher (1951).

At the beginning of the nineteenth century, attention was also directed towards the effect of air movement. Leslie suggested a form of anemometer in 1804 (Bedford and Warner, 1934) in which the cooling time of a thermometer served as a measure of air velocity. Some twenty years later, Heberden (1826) stumbled on the same idea. In his paper he 
states that, "The index of a thermometer is a very imperfect measure of what I may call sensible cold", and goes on to describe how he heated a thermometer in front of the fire until it read $120^{\circ} \mathrm{F}$. and then, taking it outside, measured the fall in temperature every ten seconds. He concludes, "The most superficial view of these experiments shows the prodigious effect of wind to increase the effect of cooling which I apprehend constitutes sensible cold".

The importance of radiant heat, especially sunshine, as a factor in determining the degree of environmental warmth had long been appreciated. Benjamin Franklin, for example, in 1729 had exposed cloth of various colours on snow in strong sunshine, and had determined, by observing the depth to which the underlying snow melted, the effect of colour on the absorption of radiant solar energy. However, it was not until 1878 that Stefan enunciated the fundamental equation $\left(\mathrm{H}=\sigma \mathrm{T}^{4}\right)$ which now bears his name.

It may be said, therefore, that by the end of the nineteenth century the importance of all four components of the environment, the temperature and humidity of the air, its speed of movement, and the intensity of radiation, had been recognized, and means were available for their exact determination in a quantitative fashion. No attempt, however, appears to have been made to evaluate, except in the most general terms, the relative importance of the contribution of each of these factors to the total environmental stress. Furthermore, the measurement of the separate factors was made largely for academic reasons and the satisfaction of intellectual curiosity.

The present position, which dates from the beginning of the twentieth century, is very different. The assessment of environmental stress is now usually directed towards some practical end-diagnostic, therapeutic, or prognostic. That is to say, it may represent an attempt to determine the intensity of the stress in a given situation, or what means should be taken to remedy a situation known to be uncomfortable or worse, or to determine whether conditions which are expected to be encountered will be acceptable to those exposed to them. This change in outlook is the inevitable result of the great increase in industrialization in the modern world with the emergence of more and more hot industries, accompanied by a change in the standards of acceptable working conditions set by employers and employees alike. Nor is the importance of these matters likely to decrease-mines tend to become deeper and industrialization is growing in the hotter parts of the world.

With this increased awareness of the importance of the thermal environment, it has come to be recognized that the effects of its separate factors, air temperature, mean radiant temperature, humidity, and air speed, can be evaluated only in the context of the rate of working of those exposed to them and the clothing worn at the time. Thus, in the assessment of the effect of any environment, attention must be given to all six of these parameters. It is inevitable, therefore, that attempts should have been made to combine the effects of two or more, or even of all six, in a single index, in order to make possible a ready comparison of situations of the most diverse kind.

The large number of such indices which, in the past fifty years, have been proposed by an even larger number of authors, provides ample evidence both of the need for such devices and the inadequacy of those that have been devised. This last statement is not to be taken as a round condemnation of indices of stress as a class. Whilst it is true that the ideal, all-embracing index is a philosopher's stone, much to be desired but most unlikely to be achieved, nevertheless, many if not most of the indices proposed are of value within a limited sphere of application. At the same time, it must be emphasized that the superficial attractiveness of an index has on many occasions led to its uncritical application with very misleading results.

Often the most difficult problem which arises when an attempt is made to assess the severity of an environment is the selection of an adequate or appropriate index. The chief purpose of this paper is, therefore, to give some account of the betterknown indices of thermal stress, to show how they conform to a restricted number of types, to indicate the general trend in their evolution, and to provide some guidance in their use for specific purposes. This has been done on a number of previous occasions, notably by Yaglou (1949) and Bedford (1936), but it is thought that recent advances justify this reappraisal.

\section{Indices of Thermal Stress}

In the account which follows, the indices have been arranged in roughly chronological order. This "historical" approach has a serious disadvantage, in that it tends to keep alive interest in devices whose shortcomings have become apparent with time and could, with advantage, be forgotten. On the other hand, it does serve to emphasize that the number of approaches to the problem is limited, and that the same fundamental idea has appeared in a variety of forms. No attempt can be made to give any but the briefest account of the more important indices which have been proposed; for details the references quoted should be consulted. 
Dry-bulb Temperature.-The dry-bulb temperature does not conform to the definition of an index as a device which combines in one value the effect of two or more factors, but it is, nevertheless, mentioned because, although the first, it still remains the most important single measure of thermal stress.

Wet-bulb Temperature.-Wet-bulb temperature can be regarded as an index which takes into consideration two factors, the temperature and the humidity of the air; the effect of air movement and radiation is disregarded. Its use as an index of thermal stress is largely due to Haldane (1905) who was convinced, as the result of his work on conditions in hot, wet mines in Cornwall, that the wet-bulb temperature provided the best measure of the physiological effects of hot environments.

The Katathermometer.-The katathermometer was devised by Hill about 1914 (Hill, Griffith, and Flack, 1916; Hill, 1919, 1920; Hill, Vernon, and HargoodAsh, 1922; Medical Research Council, 1923). Its defined purpose was "to determine if the atmospheric conditions are healthy and comfortable, and, if this is not the case, the observations may be used as an indicator whether the room is too hot or too cold, too stuffy or too draughty".

The instrument in its original form was an alcohol thermometer with a bulb $4.0 \mathrm{~cm}$. long and $1.8 \mathrm{~cm}$. wide with hemispherical ends. The stem was graduated at $95^{\circ} \mathrm{F}$. and $100^{\circ} \mathrm{F}$. and its bore was considerably enlarged at the upper end so that the instrument could be heated to well over $100^{\circ} \mathrm{F}$. without risk of damage. The manner of use was to heat the thermometer to a temperature above $100^{\circ} \mathrm{F}$. and then take the time for it to cool from $100^{\circ} \mathrm{F}$. to $95^{\circ} \mathrm{F}$. On each instrument was engraved a "factor", which represented the total heat loss per square centimetre of the instrument on cooling from $100^{\circ} \mathrm{F}$. to $95^{\circ} \mathrm{F}$. so that dividing the "factor" by the cooling time provided a measure of the "cooling power of the air". If the temperature of the air was known, its velocity could also be determined. The standard katathermometer could be converted to a "wet kata" by covering the bulb with a cotton mesh which was wetted with water. The difference between the heat loss from the dry kata (due to convection and radiation) and the loss from the wet kata provided a measure of the evaporative heat loss. Electrical and recording katathermometers were devised.

Standards, in terms of cooling power, for healthy and comfortable conditions were laid down, and for many years the instrument enjoyed wide popularity. However, as information was collected, it became apparent that sensations of comfort did not correlate well with cooling power as measured by the katathermometer, and the enthusiasm for its use waned. A more critical evaluation of the instrument followed, and the work of Bedford and Warner (1933) on the theory of the instrument led to a notable scientific advance, the introduction of the modern high-temperature silvered katathermometer, which has established itself as a very convenient and reliable anemometer. It is perhaps safe to say that the katathermometer, despite its one-time popularity, can now be discarded, except in its silvered form as an anemometer.

Effective Temperature.-The abandonment of the use of the katathermometer was perhaps hastened by the development, by the workers at the Research Laboratory of the American Society of Heating and Ventilating Engineers at the Laboratory of the Bureau of Mines, Pittsburgh, over a period from 1923 onwards, of the effective temperature scale, which early came to enjoy a wide popularity. Indeed, it has been, and continues to be, so widely used that it is justifiable to discuss its evolution at som? length.

The scale was developed first as a series of "equal comfort lines". The temperature and humidity in one test chamber were adjusted until the degree of comfort or discomfort experienced was judged by a small group of trained observers to be equal to that experienced in an adjacent test chamber maintained at a different temperature and humidity. Combinations of dry- and wet-bulb temperature satisfying this requirement were plotted on a psychromstric chart and through them a line of equal comfort was drawn. The intersection of this line with the dewpoint line defined the effective temperature of all such combinations.

When the first paper was published on effective temperature, Houghten and Yagloglou (1923a) were at pains to emphasize two points. The first was that, although their paper was entitled "Determining lines of equal comfort", these lines of equal comfort did in fact provide a valid measure of physiological effect. That is to say, all points on the same line of equal comfort (that is of equal effective temperature) produced the same degree of physiological strain. The second point was that they were aware that "this so called effective temperature scale neither indicates the temperature of the air nor that of any other object associated with the air and that the use of this term may not be in entire accordance with accepted scientific terminology". They were convinced, however, that the practical value of the term justified its adoption.

Shortly afterwards they published a further paper (McConnell, Houghten, and Phillips, 1923) again emphasizing the validity of the effective temperature 
scale as a measure of physiological effect, and, at the same time, another (Houghten and Yagloglou, 1923b) defining the comfort zone in terms of the effective temperature scale. In this paper they also stated, "After establishing these lines there was considerable criticism to calling them equal comfort lines because at high temperatures and humidity there is no comfort so we . . . call them effective temperature lines".

In these early experiments on effective temperature, little heed was paid to the amount of clothing worn, except that in experiments at high temperatures the subjects stripped to the waist to approximate conditions which would exist in industry, but it very soon came to be accepted that this type of dress should be the standard for use in all experiments. Nor was consideration given to the effect of varying air movement, attention being directed entirely to the effects of temperature and humidity, until Houghten and Yagloglou (1924) published a further paper entitled "The cooling effect on human beings produced by various air velocities". In these experiments, as before, the subjects stripped to the waist, wearing only light trousers, shoes, and socks. This was followed by two further papers on the same subject (McConnell, Houghten, and Yagloglou, 1924; Yagloglou and Miller, 1924). In all these papers, the values for the effective temperature at various air velocities were expressed not in the now familiar effective temperature nomogram, but as lines on a series of psychrometric charts or by means of tables.

In a paper published the following year (Yagloglou and Miller, 1925) the authors stated that, whereas in previous work the influence of factors such as clothing and muscular activity had been eliminated, they were now embarking on a study of the effects of these factors on the effective temperature scale, and the object of this paper was "to present a normal scale of effective temperature for ordinary conditions of life as determined with individuals normally clothed and slightly active". In this paper they also refer to their previous studies as having developed a "basic" scale of effective temperature, applicable "to all similar cases of bodily exposure such as are found in many industries when temperatures are high", and indicate the relation between the two scales. A further important aim of this paper was "to present the final results as a simple and practical chart especially for those who were not proficient in the use of psychrometric charts". The result was the nomogram for the calculation of "normal" effective temperature that is now universally used.

About the same time, a number of papers appeared dealing with other aspects of the effective temperature scale: its relation to skin temperature (McConnell and Yagloglou, 1924), a comparison with the katathermometer (Ingels, 1924), and the effect of work and clothing (Houghten, Teague, and Miller, 1926). In 1927, Yaglou, then working at the Harvard School of Public Health, published a paper on the comfort zone for men at rest and stripped to the waist (Yaglou, 1927) in which he used the now accepted nomogram for the determination of the "basic" scale of effective temperature.

Effective temperature is thus an index which provides, in a single numerical value, a measure of the combined effect of the temperature, the humidity, and the speed of the air. By the provision of two scales, "normal" and "basic", it makes a limited allowance for the effect of changes in clothing. Smith (1955) has shown that the rate at which a man works can be taken into account in connexion with effective temperature, either by the addition of a simple supplementary nomogram or by the use of a series of graphs.

Globe-thermometer Temperature.-Vernon (1930, 1932) introduced the globe thermometer as a device to measure the combined effect on thermal comfort of air temperature, air movement, and mean radiant temperature in a single index. In many circumstances, the globe-thermometer temperature provides a ready and convenient method of assessment, correlating well with the sensations experienced (Bedford, 1936). However, in the cold with cold air and still colder walls, an increase in air speed produces a rise in globe-thermometer temperature, indicating an improvement in comfort, whereas in fact the reverse occurs. Furthermore, when the surroundings and air are at the same temperature, the globe thermometer will continue to read the air temperature, irrespective of the air velocity. For these reasons its use by itself as a measure of thermal stress has been largely abandoned, but the work of Bedford and Warner (1934) has established the globe thermometer as a ready means of determining the mean radiant temperature of the surroundings, and it is now widely and successfully used for this purpose.

Equivalent Temperature.-About this time, Dufton $(1932,1933 a, b)$ introduced a scale of temperature known as "equivalent temperature", which he defined as "the temperature of a uniform enclosure in which, in still air, a sizeable black body at $75^{\circ} \mathrm{F}$. would lose heat at the same rate as in the environment in question". That is, equivalent temperature is a measure of the combined effect of the temperature and speed of the air and the temperature of the surroundings.

To measure this "equivalent temperature" he 
invented an ingenious instrument called the eupatheoscope-a blackened copper cylinder 22 in. high and 7.5 in. in diameter, the surface of which was maintained by internal electric heaters at a constant temperature of $75^{\circ} \mathrm{F}$. The required heat input was read or recorded directly in terms of the equivalent temperature of the environment. It is interesting to observe that he first called his scale "effective" temperature, but the term "equivalent" was substituted to avoid confusion with the recently introduced American scale of effective temperature. Bedford (1936) devised a nomogram by means of which the equivalent temperature of an environment can be determined from the measurements of the individual thermal factors.

Thermo Integrator.-About the year 1935, the workers at the John B. Pierce Laboratory of Hygiene undertook a long series of experiments to develop a new method of partitional calorimetry (Winslow, Herrington, and Gagge, 1936a, b; Gagge, 1936, 1937; Gagge, Herrington, and Winslow, 1937; Herrington, Winslow, and Gagge, 1937) by means of which, for a subject in equilibrium, the total heat exchange with the environment could be partitioned between the three avenues of evaporation, convection, and radiation. As a by-product almost of this work, substantial contributions, such as the concept of "the per cent wetted area" (Gagge, 1937), were made to the physiology of temperature regulation. It also produced as a by-product, the thermo integrator (Winslow, Gagge, Greenburg, Moriyama, and Rodee, 1935). This was a blackened copper cylinder with hemispherical ends 24 in. long and 8 in. in diameter. The interior was evacuated and through it passed a heating element of nichrome wire supplying a constant heat input. Thermocouples on the outer surface measured the mean surface temperature of the instrument at the balance between heat input and heat loss. It was intended for use as a measure of the combined influence of air temperature, air movement, and radiation upon human comfort. It is frequently mentioned in the literature, but appears to have been seldom used.

Operative Temperature.-The concept of operative temperature (Gagge et al., 1937; Winslow, Herrington, and Gagge, 1937a, b) was another by-product of the work on partitional calorimetry. It was intended as a measure of the net physical effect of the surrounding walls and ambient air temperature. It was defined by the equation

$$
T o=\frac{K r T w+K c T a}{K r+K c}
$$

and represented the mean of the wall temperature $(T w)$ and the air temperature $(T a)$ weighted according to the respective effectiveness of the process of radiation and convection as measured by the respective constants $K r$ and $K c$. When air and wall temperatures are the same, the operative temperature is equal to the air temperature. When air and wall temperatures are not greatly different, $T o$ can be taken to be the arithmetical mean of the two. For a given operative temperature, the air movement was assumed to have a constant speed of $17 \mathrm{ft}$./min.

This simple relation between operative and air temperature is fortunate, as the valuable and often quoted physiological findings of the authors are all expressed in terms of operative temperature. The concept of operative temperature implies that a given heat exchange, irrespective of the respective magnitude of the radiation and convection components, produces the same effect. This is not necessarily so, and this fact appears to have been recognized by its authors (Herrington et al., 1937).

Standard Operative Temperature.-The concept of operative temperature was later extended to the case where larger variations in air movement were present (Gagge, 1941). In its new form it was given the name "standard operative temperature" and was defined by the equation,

$$
\begin{aligned}
S T o= & \frac{K}{1+K}(T w)+ \\
& \frac{1}{1+K}[(\sqrt{V / V o}) T a-(\sqrt{V / V o}-1) T s]
\end{aligned}
$$

where $T w, T a$, and $V$ are respectively the observed wall temperature, air temperature, and air movement. $K$ represents the ratio of the radiation and convection constants at the reference air movement $(\mathrm{Vo})$ of $7.6 \mathrm{~cm} . / \mathrm{sec}$.

Standard operative temperature defines an imaginary environment of equal wall and air temperatures and air movement $V o$, in which the human body, with skin temperature $T s$, would lose the same amount of heat by radiation and convection as in the original environment.

It will be observed that the effect of the humidity of the air is neglected as this, in general, will not affect the total amount of heat loss by evaporation.

Cooling Power of the Atmosphere (Wind-chill Index).- - From a consideration in Antarctica of the freezing time of $250 \mathrm{~g}$. of water in a plastic cylinder 
suspended freely in variable atmospheric conditions whose temperature and wind velocity were known, Siple and Passel (1945) derived the following equation

$$
K o=(\sqrt{v \times 100}+10.45-v)(33-T a)
$$

where $K o$ is defined as the cooling power of the atmosphere $\left(\mathrm{kcal} / \mathrm{m} .{ }^{2} / \mathrm{hr}\right.$.), $v$ is the wind velocity (m./sec.), and $\mathrm{Ta}$ the temperature of the air $\left({ }^{\circ} \mathrm{C}\right.$.).

Solutions of the equation for values of $T a$ and $v$ were provided in the form of tables and a scale of the effect of various levels of wind chill from 0 (uncomfortably warm) to 2,500 (the coldest conditions encountered and in which exposed flesh freezes in less than $30 \mathrm{sec}$.).

This index has attracted a great deal of criticism. Molnar (1960) has indubitably shown that the calculations on which the heat lost from the cylinder was based were in error. Nevertheless, Burton and Edholm (1955), although they agree that "it has no scientific basis", consider that the sensations experienced in the cold correlate well with the windchill index. This view has received strong support recently from Palmai (1962), and Goldsmith (1960) considers it the best index available in the cold, despite its shortcomings.

Index of Physiological Effect.-Robinson, Turrell, and Gerking (1945) studied the physiological responses of five men to exposure for a period of some hours to a range of hot environments. Three rates of energy expenditure were studied, sitting, walking at $4.5 \mathrm{~km}$. $/ \mathrm{hr}$., and walking at $5.6 \mathrm{~km}$. $/ \mathrm{hr}$. up a $2.5 \%$ grade. The men were clothed in shorts or in army jungle uniforms. The effects of only one air speed, $55 \mathrm{~m}$./min., were examined, and the walls were kept at air temperature.

From the results of the experiments an index of physiological effect $(E p)$ was devised, which may be defined as

$$
E p=E h+E s+E r+E w
$$

where $E h, E s, E r$, and $E w$ are respectively a measure of the effect of exposure on the heart rate, the skin temperature, the rectal temperature, and the sweat loss.

$$
E h \text { was defined as } \frac{H_{3}-H_{1}}{H_{2}-H_{1}} \times 100 \text {, where } H_{1} \text { was }
$$

the resting heart rate in a cool environment, $\mathrm{H}_{2}$ the heart rate in the most severe environment which could be tolerated, and $H_{3}$ the heart rate in the environment being evaluated. The other indices, $E s, E r$, and $E w$, were similarly calculated. Contour lines were then drawn on a psychrometric chart indicating selected values for $E p$. The level at which thermal equilibrium could be just maintained, that is to say the beginning of the zone of body heat accumulation, which served to mark off tolerable from intolerable levels of warmth, was also determined. For working men under a variety of conditions, this accorded approximately with a value of $E p$ of 200 , but in the case of men sitting at rest it was closer to an $E p$ value of 300. In general, the slope of the contour lines followed the slope of the effective temperature lines and to this extent provided confirmation of earlier work. It is important to note that these results and the method as a whole can be applied only to acclimatized men. Other workers seem to have made little use of this index. It has been criticized by Yaglou (1949) on the grounds that any one of the four variables may approach a critical value, irrespective of the other three and without necessarily raising the index to a value which indicates intolerable conditions.

Thermal Acceptance Ratio.-The thermal acceptance ratio, which was proposed (Ionides, Plummer, and Siple, 1945; Plummer, Ionides, and Siple, 1945) as a measure of heat stress, represented a new approach to the problem. It may be defined as

$$
R a=H a / M
$$

where $R a$ is the thermal acceptance ratio, $H a$ is the heat acceptance of the environment (defined as the rate at which the environment in question is capable of accepting heat from an unclothed person if his skin temperature is maintained at an assumed safe limit of $97^{\circ} \mathrm{F}$.), and $M$ is the rate of heat production of the body.

$\mathrm{Ha}$ is calculated from the formula

$$
H a=E k(44 \cdot 8-p a)+C k(97-T a)+R k(97-T w)
$$

where $p a$ is the vapour pressure of the air, Ta the temperature of the air, and $T w$ the temperature of the surroundings. Ek, $C k$, and $R k$ are experimentallydetermined evaporative, convective, and radiation constants. The evaporative heat loss is assumed to have an upper limit of $500 \mathrm{kcal} / \mathrm{m} .{ }^{2} / \mathrm{hr}$.

When the thermal acceptance ratio was plotted against the observed sweat loss, heart rate, and rectal temperature in a range of thermal environments smooth curves were obtained, whose shape depended upon the measure of physiological strain chosen.

In its present form, the scope of the index is restricted. It is applicable only in hot, not in cold, conditions, and relates only to the unclothed subject. It remains to be shown that the assumption that tolerance of heat is determined by a skin temperature 
of $97^{\circ} \mathrm{F}$. is correct, and considerable uncertainty exists concerning the precision with which it is possible to calculate the amount of heat which can be transferred through the several avenues of heat exchange.

Despite these shortcomings, the underlying idea of the thermal acceptance ratio is attractive, and, though it itself appears not to have been used to any extent in practice, its relation to other indices, such as that of Belding and Hatch, which is described later, is clearly apparent.

Corrected Effective Temperature.-Effective temperature, as defined by the Pittsburgh workers, takes no cognisance of the temperature of the surroundings. However, in situations in which heat stress commonly occurs, in mining, metal working, and engine and boiler rooms, the temperature of the surroundings is often considerably elevated above air temperature. Bedford (1946) suggested that the effective temperature scale could be adapted to embrace such conditions if the globe-thermometer reading was substituted for the dry-bulb temperature in the effective temperature nomograms. He deliberately refrained from correcting the wet-bulb, as had been suggested by Vernon and Warner (1932), in order to retain the admirable simplicity of the existing scale of effective temperature. Subsequent experimental work (Macpherson, 1960) has amply confirmed the validity of Bedford's suggestion.

Predicted Four-hour Sweat Rate.-More shortly known as the P4SR, this index was developed by McArdle and his co-workers at the National Hospital, London (McArdle and Dunham, Holling, Ladell, Scott, Thomson, Weiner, 1947), and was devised largely because these workers had observed apparent anomalies in the effective temperature scale. It expresses, by means of an empirically-devised nomogram, the stress imposed by a hot environment in terms of the amount of sweat which would be secreted by fit, acclimatized young men when exposed to the environment in question for a period of four hours. It also provides a method for determining the rectal temperature at the end of the exposure. Such an index can strictly only be applied in situations in which sweating occurs, although the scale does make provision for small negative values of the P4SR. Though the authors of the scale adjusted the value of the P4SR in those cases in which they considered the observed sweat loss to provide an inadequate measure of the stress imposed, as indicated, for example, by the body temperature, the P4SR has been shown to predict the actual sweat loss over a wide range of conditions with remarkable accuracy.
This index of heat stress represented a considerable advance over previous indices, as it takes into consideration not only the environmental factors of the temperature, humidity, and movement of the air and the temperature of the surroundings, but also the rate of energy expenditure and the clothing worn in the environment. It is restricted to use indoors with upper limits of air or globe-thermometer temperature of $130^{\circ} \mathrm{F}$., wet-bulb temperature of $98^{\circ} \mathrm{F}$., and an air speed of $500 \mathrm{ft} . / \mathrm{min}$. It could, undoubtedly, be used in the shade out of doors, but no systematic attempt seems to have been made, nor does it appear to be suitable for use in direct sunlight. The original paper (McArdle et al., 1947) is relatively inaccessible, but it has been reprinted as an appendix to M.R.C. Special Report Series No. 298 (Macpherson, 1960).

Equivalent Effective Temperature Corrected for Radiation.-This index, proposed by Yaglou, Baetjer, Machle, McConnell, Shaudy, Winslow, and Witheridge (1950), represents another attempt to incorporate the effects of radiation exchange within the framework of the effective temperature. They suggest that such a correction could be made by using the globe temperature instead of the dry-bulb temperature with the given dew point (not the given wet-bulb) and the given air movement in computing the equivalent effective temperature from the standard nomograms. An example helps to make the method plain. Assume that the conditions are dry-bulb $85^{\circ} \mathrm{F}$., wet-bulb $70^{\circ} \mathrm{F}$., globe-thermometer reading $100^{\circ} \mathrm{F}$., and air speed $100 \mathrm{ft}$./min. The dew point, as determined by a psychrometric chart, is $63^{\circ} \mathrm{F}$., then the equivalent wet-bulb temperature corresponding to a globe temperature of $100^{\circ} \mathrm{F}$. and a dew point of $63^{\circ} \mathrm{F}$. is $74^{\circ} \mathrm{F}$. The corrected effective temperature is then calculated as for drybulb temperature of $100^{\circ} \mathrm{F}$., wet-bulb temperature of $74^{\circ} \mathrm{F}$., and air speed of $100 \mathrm{ft}$. $/ \mathrm{min}$. This method differs only from that of Bedford in the use of a correction for the wet-bulb temperature.

Index for Evaluating Heat Stress. - This index was devised by Belding and Hatch $(1955,1956)$ following a proposal by Haines and Hatch (1952) for the evaluation of the magnitude of the heat exposure in hot industries based on the previous work of Nelson, Eichna, Horvath, Shelley, and Hatch (1947).

Haines and Hatch proposed that the total heat load of the man exposed should be determined from his known rate of energy expenditure, the radiation exchange with his surroundings calculated from the formula,

$$
R=e K A r\left(T w^{4}-T s^{4}\right),
$$


and his convection heat exchange calculated from the formula

$$
C=K c A c(t s-t a),
$$

where $e$ is the emissivity of the human body, $K$ the universal radiation constant, $A r$ the effective radiation area of the body, $T w$ and $T s$ the mean radiant and skin temperature respectively in ${ }^{\circ} \mathrm{F}$. absolute, $K c$ an experimentally determined convection coefficient, $A c$ the effective convection area, and $t s$ and $t a$ skin and air temperature in ${ }^{\circ} \mathrm{F}$. The maximum evaporative capacity of the man, assuming the skin to be completely wetted, could also be calculated from the formula

$$
E_{\text {max }}=\operatorname{Ke} A e(P s-P a),
$$

where $K e$ is an experimentally determined evaporation coefficient, $A e$ the effective evaporation area, and $P s$ and $P a$ the water-vapour pressure on the skin and of the air respectively. Comparison of the total heat loss with the maximum evaporative capacity of the air would then serve to show whether thermal equilibrium could be maintained in the environment in question. A series of charts and diagrams was provided in the paper to simplify the calculation.

Belding and Hatch $(1955,1956)$ took the matter a stage further when they suggested as an index for evaluating heat stress in terms of resulting physiological strain the value of

$$
\frac{E_{\text {req }}}{E_{\text {max }}} \times 100
$$

that is to say, the percentage relation between the evaporative requirements to achieve thermal equilibrium and the maximum evaporative capacity of the air, assuming the skin to be completely wetted and its temperature $95^{\circ} \mathrm{F}$. In conditions of low vapour pressure, however, the evaporative capacity of the air can exceed the capacity of the body to produce sweat, so that an upper limit of $2400 \mathrm{BTU} / \mathrm{hr}$. was placed on ' $E_{\text {max }}$ ', which corresponds to the secretion of one litre of sweat per hour.

When the values of the index were plotted as a series of contour lines on a rsychrometric chart, they corresponded well with the contour lines plotted from the data of physiological experiments by others. Values of the index exceeding 100 would indicate that heat storage was occurring, but it must be remembered that equilibrium could be maintained in environments for which the calculated index value exceeded 100 if the skin temperature of the subject concerned exceeded the assumed upper limit of $95^{\circ} \mathrm{F}$.

The validity of this method of predicting heat stress depends upon the validity of a number of assumptions and approximations, and its reliability will only be determined by experience in its use. In a recent paper, Belding, Hertig, and Riedesel (1960) report the investigation of a case in which the index clearly overestimated the stress of the environment. Laboratory studies subsequently showed that the heat strain was substantially less than that indicated by the index. This was attributed to blocking of about $40 \%$ of impinging radiation by the ordinary work clothing that was worn. Such anomalous cases do not destroy the essential validity of the method, but merely serve to indicate the necessity for caution until experience has been gained in its use by the comparison of observed and predicted results in actual work conditions.

Wet-bulb Globe Thermometer Index (WBGT).This is a simple index devised by Yaglou and Minard (1957) for the control of heat casualties at military training centres in the United States of America. It embraces, in a single value, the effects of radiation from the sun and terrain, air temperature, humidity, and wind speed. In its final form (Departments of Army, Navy and Air Force, Washington, 1957) it was defined as

$$
\text { WBGT }=0.7 \text { W.B. }+0.2 \text { G.T. }+0.1 \text { D.B. }
$$

where W.B. is the wet-bulb temperature, G.T. the glote-thermometer reading and D.B. the dry-bulb temperature.

In the latter publication detailed instructions concerning the instruments required and their manner of use for determining the three separate readings are also given.

This publication also sets out the activities which may be followed at various levels of the index without serious risk of incurring heat illness. Its comprehensiveness, its simplicity, and the fact that it can be used out of doors make it extremely suitable for the purpose for which it was devised.

Thermal Strain Index.-Lee (1956, 1958) has devised a thermal strain index, based partly on heat-transfer mechanisms and partly on observations of the reaction of the body to increasing heat stress. Lee observed that when combinations of temperature and humidity which had been reported to produce the same physiological effect are plotted on a psychrometric chart, lines of equal physiological strain conform to a definite pattern. With increasing heat stress they undergo a rotation from a position in which they are parallel to the dry-bulb axis in neutral conditions to take up a position approximately parallel to the wet-bulb lines at high levels of heat stress. This change in slope, it was argued, can reasonably be attributed to the increasing importance of evaporative regulation. He, therefore, devised an equation, involving the temperature, humidity, 
and speed of the air, and the rate of energy expenditure and clothing worn by those exposed, to calculate an empirical index of thermal strain, in which the value so calculated followed the observed pattern when plotted on a psychrometric chart. Except that the slope differs, these lines are very similar to the lines of equal comfort on which effective temperature is based. Levels of comfort and/or discomfort and tolerance times under a wide variety of conditions were defined in terms of the new index.

Equatorial Comfort Index.-This index has been recently introduced by Webb $(1959,1960)$ and is based on a comfort-vote survey embracing representatives of the several races living in Singapore. From the findings of this survey, a multiple regression equation was devised expressing the degree of comfort in terms of the environmental factors of temperature, humidity, and air speed. The results are conveniently expressed in the form of a nomogram similar to those used for the calculation of effective temperature. The index is expressed as the temperature of still air saturated with water vapour, which is equivalent physiologically to the climate under consideration.

It is reasonable to believe that this index will provide a more accurate measure of equivalent conditions of warmth than the effective temperature scale in equatorial regions, because it is based on assessments by those who are habitually exposed to the climate concerned.

\section{Types of Indices}

No less than 19 indices for the assessment of the thermal environment have been listed in the previous section, but it is clear that there is a strong family resemblance between many, and they may be conveniently grouped into three main classes, namely those which are based on the measurement of the physical factors in the environment, those which are based on a measurement of the physiological strain produced by the environment, and those based on the calculation of the heat exchange between the body and its environment.

Indices Based on Measurement of Physical Factors.-Among these indices may be included drybulb temperature, wet-bulb temperature, cooling power, equivalent temperature, and globe-thermometer temperature. All these indices include air temperature, some combine this with the air movement and the temperature of the surroundings, and some (the wet kata cooling power and the wetbulb temperature) include the effects of humidity.

These indices, although they provide a measure of the environmental factors, provide no direct measure of the physiological effect. That must be secondarily derived from consideration of the effect on those exposed to them of conditions for which the value of the index has been determined. This may be achieved on the basis of common experience alone, as with dry-bulb temperature, or on the basis of a series of formal experiments, as Haldane (1905) did with the wet-bulb temperature, or on the results of surveys using variants of the comfort-vote technique, for example the work of Bedford (1936) or Hickish (1955).

When told in the weather forecast that the air temperature tomorrow will be $85^{\circ} \mathrm{F}$. we know from previous experience that this temperature will be uncomfortably warm and from memories of previous experience of such temperatures we can arrive at a fair estimate of the degree of discomfort that will be experienced. However, in general, no such universal appreciation is attached, for example, to the information that the cooling power as measured by the katathermometer is 10 . The growing practice of quoting air temperatures in degrees Centigrade further illustrates this point. The same person who appreciated well the significance of $85^{\circ} \mathrm{F}$. might not comprehend the significance of the information that the forecast temperature would be $29 \cdot 5^{\circ} \mathrm{C}$.

It will be noticed also that in those indices in which more than one environmental factor is taken into consideration a device is commonly invented to integrate the effects of the factors considered. It might be even fair to say that a single type of device is invented, because there is a strong resemblance between Heberden's thermometer, the katathermometer, the eupatheoscope, the globe thermometer, the thermo integrator, and the plastic cylinder used for the calculation of wind chill. The use of such devices has now been largely abandoned. The explanation is that they represent inadequately, for other reasons as well as shape and size, the effect of the environment on the human body.

Indices Based on Physiological Strain.-In this group may be placed the effective temperature scale and its modifications (including corrected effective temperature, equivalent effective temperature corrected for radiation, and the equatorial comfort index), the index of physiological effect, the predicted four-hour sweat rate, the index for evaluating heat stress proposed by Lee, and probably the WBGT index. In designing these indices, the approach has been to expose a group of test subjects to a wide range of environmental conditions and then, by analogy with Hooke's Law, conclude that conditions of equal environmental stress are those 
which produce an equal physiological strain. The relation between the value of the separate factors and the strain produced can be expressed in the form of a multiple regression equation or, more commonly for convenience, in the form of a nomogram.

The clearest example of this type of index is the P4SR of McArdle et al. In devising it, men were exposed to many different combinations of air temperature, humidity, air speed, and mean radiant temperature whilst wearing different levels of clothing and performing work at different rates. The measure of physiological strain used was the amount of sweat secreted in four hours, and those situations in which equal amounts of sweat were produced were considered to exert an equal stress on those exposed. The severity of different environments could be contrasted and upper limits of tolerance defined in terms of the sweat produced. The index of physiological effect $(E p)$ differs only in that several measures of physiological strain were used in combination to measure the environmental stress.

Such indices also commonly make use of a series of contour lines drawn on a psychrometric chart. This was done originally in the effective temperature scale, it was used in the index of physiological effect and again in the thermal strain index. It is a useful and convenient means of displaying the combined effects of temperature and humidity, but the introduction of other factors makes the method inconveniently complicated.

At first sight it may seem strange that the effective temperature is included in this group. It is based solely on sensations of comfort, but comfort or discomfort properly measured can be considered to be a valid index of physiological strain and used accordingly.

It is thought fair also to include in this group the WBGT index of Yaglou and Minard. In this, the index is calculated from an equation in which the values for the wet-bulb, dry-bulb, and globethermometer temperatures are each weighted by an appropriate constant, determined in this case by experience, to ensure that the index provides a satisfactory measure of the strain produced. The method is in every respect similar to that used in other indices of this type.

Indices Based on the Calculation of Heat Exchange.-Indices in this group include the thermal acceptance ratio of Plummer, Ionides, and Siple and the index devised by Belding and Hatch. In this group also should be included, it is thought, operative temperature and standard operative temperature.

The underlying principle of the indices, that of calculating the heat exchange between the body and its environment, has much to recommend it. It represents an escape from empiricism and an attempt to establish an index on the rational basis of heat transfer. But the escape from empiricism is not as complete as appears at first sight. The calculation of heat transfer involves the use of experimentally determined coefficients and assumptions concerning the behaviour of skin temperatureespecially what constitutes an acceptable skin temperature.

Even if the uncertainty attached to the calculation of the quantity of heat transferred could be removed, a further difficulty would remain in that the body can differentiate between two avenues of heat exchange. Their physiological effect may not be equal to their algebraic sum. For instance, one's face may be painfully heated by the fire whilst one's back is chilled by the draught. Nor does the accurate calculation of the amount of heat transferred, or even its ratio to the total amount which can be transferred, indicate in itself the severity of conditions. This can only be determined experimentally or in the light of experience. Nevertheless, it is considered that this method provides the most satisfactory approach to the problem of the multiplefactor index yet devised, and future advances may well be made in this direction.

\section{The Trend in Evolution}

The trend in evolution is plain from the previous section. The measurement first of the single factor in the environment and then of several factors, the combining of these factors in a single index, usually by means of some device, the use of physiological strain as a measurement of environmental stress and, finally, the calculation of heat transfer.

Although this represents the general trend, there has been considerable overlapping, and it cannot be taken that subsequent indices have necessarily superseded earlier forms. This point will be discussed further in the next section.

\section{The Choice of an Index}

Even if we exclude from the list of indices which have been discussed those that were stillborn, those which time has shown to be of little value, and those which are as yet relatively untried, there still remains a wide range from which a choice may be made. Before consideration is given to the choice of an index for a specific purpose, it is profitable first to consider the general principles to be considered in the selection of an index.

General Principles.-It may be as well to begin with a warning - that the assessment of the thermal 
environment is not primarily a matter of the selection of some thermal index in which to express the results. Expressing the results in the form of an index may be a convenience, but the assessment of the environment is essentially the measurement of all the factors concerned, whether they are attributes of the environment, such as air temperature and humidity, or attributes of those exposed, such as their clothing, rate of working, and length of exposure. The means whereby the thermal factors may be assessed have been conveniently set out by Bedford (1946). Remedial measures cannot be undertaken unless all these measurements have been made and the situation analysed in the light of the findings. A suitable index may then be of help in determining the effect of proposed remedial measures.

Indices of thermal stress do not provide a substitute for a sound knowledge of the mechanisms of heat exchange and of the physiological adjustments to the thermal environment, and some further warnings are necessary.

There may be inbuilt errors in the selected scale of warmth. In warm atmospheres the physiological reactions closely follow the effective temperature index. Nevertheless, the effective temperature scale is undoubtedly in error in the effects it attributes to humidity at low temperatures, and to the effects of wind speed at high air temperatures. Overestimation of the effect of humidity at low temperatures was due, as Yaglou (1949) points out, to failure to recognize the thermal effects accompanying sorption of moisture by clothing. The effect of air speed, as represented on the effective temperature scale, below the point at which crossover occurs, is one of increasing amelioration with increasing air speed. However, as McArdle et al. (1947) clearly showed, the effect of air movement is complex, and at high air temperatures, i.e. above skin temperature, whether the beneficial effect of enhanced evaporation will outstrip the undesirable effect of increased heat gain by convection depends upon the humidity, the clothing worn, and the rate at which the subjects are working. It often takes the form of an initial improvement as the air speed increases from zero, followed by a progressive deterioration as the air speed increases further. These limitations must be appreciated in applying effective temperature to practical problems.

It is important to notice also that the two scales of effective temperature are not interchangeable. For example, at a condition of say $80^{\circ} \mathrm{F}$. on the basic effective temperature scale, a man stripped to the waist will experience the same degree of comfort or discomfort as he would in a still, saturated environment at a temperature of $80^{\circ} \mathrm{F}$. Similarly, a man normally clothed at an effective temperature of $80^{\circ} \mathrm{F}$. on the normal effective temperature scale will experience the same sensations as he would when clothed in the same way in a still, saturated environment at $80^{\circ} \mathrm{F}$. But the sensations he would experience in still, saturated air at $80^{\circ} \mathrm{F}$. would be different when dressed in these two different ways. Stripped to the waist, it should be added, means wearing long trousers, boots and socks, not barefooted and wearing shorts, as some have assumed.

Interpretation of the significance of the value obtained for the chosen index often presents difficulties. Linearity has often been stated to be a desirable attribute of scales of warmth, and effective temperature has been criticized for its lack of linearity. The physiological effect of an increase of $1^{\circ} \mathrm{F}$. effective temperature is much greater at 90 than at $80^{\circ} \mathrm{F}$. effective temperature. Experience would seem to show that this is not as important as it seems. We must beware of attempting to read too much into a scale. It can be accepted, though formal proof is lacking, that a P4SR of 2 represents a greater stress than a P4SR of 1, but how much greater it is impossible to say. It is improbable that it is precisely twice as great. One of the advantages claimed for the P4SR is that from it it is possible to predict the actual sweat loss of fit, acclimatized young men with considerable accuracy, but, when due allowance is made for curvilinearity, effective temperature predicts sweat loss with comparable exactitude (Smith, 1955). Similarly, "very hot" on a scale of comfort indicates something worse than "hot", but how much worse cannot be determined. This difficulty in the analysis of subjective reactions can be avoided (Chrenko, 1955) by the use of probit analysis, i.e. treating the subjective reactions as a quantal response. The subject can state with precision whether he feels hot or cold or neither hot nor cold, but a lack of precision becomes apparent when the degree of heat or cold has to be determined.

It is important to remember also that there are factors which modify the physiological strain produced by the environmental stress which are not, or cannot be, included in an index. The most important of these is acclimatization, and it undoubtedly applies both to heat and to cold. Some indices, notably the index of physiological effect and the predicted four-hour sweat rate, are specifically determined in terms of their effect on acclimatized men, but, in general, this is not so. A homely reminder of the effects of acclimatization is to be seen in the variation in the preferred temperature observed in different climates and at different times of the year, although other factors, such as clothing, no doubt also play a part (Hindmarsh and Macpherson, 1962). 
There are other factors which, though probably less significant than acclimatization, are at the same time more difficult to evaluate. Such are age, possibly sex, and certainly health-myxoedema is accompanied by an increasing sensitivity to cold stress.

The choice of units in which some indices are expressed is often misleading. Those who devised the effective temperature scale were well aware of the objections which could be raised to the use of the term "effective temperature". Similarly, to speak of predicted four-hour sweat rate of " $x$ litres" is open to objections. Strictly speaking, what is determined is an adjusted weight loss, not the actual volume of sweat secreted, and certainly not the rate at which sweat is secreted. It would be better simply to express it as a dimensionless index. The expression of wind chill in $\mathrm{kcal} / \mathrm{m} .{ }^{2} / \mathrm{hr}$. has misled some into thinking that it is the rate at which the body loses heat when exposed to the conditions in question. It might well disarm criticism of this very useful measure if it were also expressed as a dimensionless index.

Uncertainty also surrounds the meaning of such expressions as "upper desirable", "upper acceptable" or "upper tolerable" levels of warmth which are commonly used in association with the assessment of thermal stress. This matter has been discussed elsewhere (Macpherson, 1960) and it is sufficient here to draw attention to their lack of precision and their interpretation in different ways by different authors. Limits of tolerance based on the physical capacity to withstand the environment are of very restricted value, because, as Ellis (1953) has clearly demonstrated, before actual physical incapacitation occurs there may be such deterioration in mental capacity as to render the subject completely ineffective.

It may be a counsel of perfection, but what these warnings imply is that before proceeding to make use of an index the user should satisfy himself, by reference to the original papers, that it was devised for use in conditions comparable to those in which he intends to use it, and, furthermore, by reference to the work of those who have used the index, satisfy himself that it does indeed meet the needs for which it was devised.

The Uses of Indices for Specific Purposes.-The first matter on which one must satisfy oneself in selecting an index for a specific purpose is that the index chosen covers the correct range of temperatures. The scale of equivalent temperature, for example, does not extend beyond $75^{\circ} \mathrm{F}$. Some, such as the wet-bulb temperature and the P4SR, are applicable only in the range in which sweating occurs, wind-chill index applies only in conditions of moderate to intense cold, and the effective temperature scale finds its greatest use in the middle range of heat stress.

If there is a choice of two indices, choose the simpler. The simpler the index chosen the more likely it is to prove satisfactory, and the simplest index of all is the dry-bulb temperature. If an index is to be used for comparing two situations in which the rate of work is the same and the amount of clothing worn subject to little variation, there is no special advantage in selecting an index which embraces these factors, and in cold conditions variations in humidity can be safely neglected.

As an example of the application of these principles, we may consider defining the level of comfort for indoor workers for the purpose of air conditioning. In this case air temperature by itself provides a satisfactory measure, and a little consideration will serve to show the reasons for this. Indoors the people concerned are usually clad alike, they are either sedentary or engaged in very light activities, air movement does not vary greatly from place to place, and the temperature of the surrounding walls, unless they contain heating or cooling devices, will be at the same temperature as the air.

There remains then the question of humidity. As we are concerned with conditions of comfort, it can be assumed that sweating does not occur and heat loss by evaporation is confined to water loss from the lungs and insensible perspiration from the skin. These together constitute only about one-fourth of the heat exchange in comfortable conditions. Any variations in evaporative heat losses which may occur with any but the most extreme variations in humidity will, therefore, be small and can be accommodated by adjustment in the heat loss by convection and radiation. A recent investigation by Koch, Jennings, and Humphreys (1960) has confirmed this point of view. It was found that in the optimum comfort range a change from $30 \%$ relative humidity to $85 \%$ relative humidity was equivalent only to a change of dry-bulb temperature of $1 \cdot 1^{\circ} \mathrm{F}$. This confirms an earlier finding by Bedford (1948) that a change of $50 \%$ relative humidity was equivalent to a change of $2^{\circ} \mathrm{F}$. in the dry-bulb. Yaglou (1949) expressed much the same views when he said that under ordinary conditions in still air the dry-bulb temperature in itself is a better index of warmth than is effective temperature or any other composite index.

As a contrasting example, we may consider comparing conditions in hot, wet mines. Here, and in other situations in which the humidity is high, the air speed low or constant, the air temperature near 
skin temperature, and the heat exchange, in consequence, confined to loss by evaporation, the wetbulb temperature provides an adequate means for assessing the thermal environment and, indeed, has been so used for many years. If substantial variations in air speed occur or the air is very hot and dry, then wet-bulb temperature by itself is inadequate and either the P4SR or the effective temperature scale in one of its forms should be used. If there is a large radiation component in the environment, then the effective temperature scale used should be one containing a correction for radiation. Consideration should also be given to the use for this purpose of the index devised by Belding and Hatch.

A statistical evaluation of the risk of heat stroke has recently been proposed (Wyndham, 1961; Winer, Maritz, and Wyndham, 1962) as a guide to the severity of hot conditions in mines. This may be regarded as an example of the type of index based on physiological reactions-if we regard grave injury or death, the ultimate disaster which results from exposure to high levels of heat stress, as a physiological reaction. Although the field of application of such an index must be severely restricted, for reasons which have already been given, it may be of value in special circumstances. A military commander might well be glad of such information for strategic or tactical reasons, and in crises in civilian life, such as rescue operations following a fire or an explosion in a mine, it might also prove of value to those who have to make decisions.

In hot industries within doors there is a wide range of choice. The P4SR, although the sphere of application for which it was devised was between decks in ships at sea, is a very suitable index for use in such situations.

An important situation which has as yet been strangely neglected is exposure to high levels of heat stress out of doors where to the burden of high air temperatures is added the solar heat load. In view of its importance, this neglect is serious. The situation applies not only to agricultural workers and those engaged in other rural pursuits whom we commonly think of as being exposed to the sun, but also many industrial workers, including those engaged in the erection of buildings, for whom high levels of heat stress are an added hazard in an already hazardous occupation. It is, of course, a situation of the very greatest importance to military forces both when they are engaged in training or in battle. Indeed, the only index specially designed for use in this connexion is the WBGT index of Yaglou and Minard. Further work, including the evaluation of this index, is urgently needed in this important field.

\section{REFERENCES}

Bedford, T. (1936), Rep. industr. Hlth Res. Bd (Lond.), No. 76.

(1946). War Memor. Med. Res. Coun. (Lond.), No. 17.

(1948). Basic Principles of Ventilation and Heating. Lewis, London.

—-, and Warner, C. G. (1933). J. Hyg. (Lond.), 33, 330.

(1934), ibid., 34, 458.

Belding, H. S., and Hatch, T. F. (1955). Heat. Pip. Air Condit., 27, (8), 129. (1956). Trans. Amer. Soc. Heat. Air Condit. Engrs., 62, 213. Hertig, B. A., and Riedesel, M. L. (1960). Amer. industr. Hyg.

Ass. J., 21, 25.
Blagden, C. (1775a). Phil. Trans., 65, 111.

(1775b). ibid., 65, 484.

Burton, A. C., and Edholm, O. G. (1955). Man in a Cold Environment. Arnold, London.

Chrenko, F. A. (1955). J. Instn Heat. Vent. Engrs, 23, 281.

Departments of Army, Navy and Air Force, Washington (1957). TB MED 175, NAVMED P-5052-5, AFP 160-4-1A.

Dufton, A. F. (1932). Building Research Technical Paper No. 13 H.M.S.O., London.

- (1933a). J. Hyg. (Lond.), 33, 349.

Ellis, (1933b). ibid., 33, 474 .

Ellis, F. P. (1953). Ann. roy. Coll. Surg. Engl., 13, 369.

Ellis, H. (i758). Phil. Trans., 50, 754.

Gagge, A. P. (1936). Amer. J. Physiol., 116, 656.

(1937). ibid., 120, 277.

(1941). In Temperature. Its Measurement and Control in Science and Industry, p. 544. Reinhold, New York.

Herrington, L. P., and Winslow, C.-E. A. (1937). Amer. J. Hyg., 26, 84.

Goldsmith, R. (1960). J. appl. Physiol., 15, 776

Haines, G. F., and Hatch, T. (1952). Heat. \& Ventilating, 49, November, 93

Haldane, J. S. (1905). J. Hyg. (Lond.), 5, 494.

Heberden, W. (1826): Phil. Trans. 117, 69.

Herrington, L. P., Winslow, C.-E.A., and Gagge, A. P. (1937). Amer. J. Physiol., 120, 133.

Hickish, D. E. (1955). J. Hyg. (Lond.), 53, 112.

Hill, L. (1919). Spec. Rep. Ser. med. Res. Coun. (Lond.), No. 32. (1920). ibid., No. 52.

, Griffith, O. W., and Flack, M. (1916). Phil. Trans. B, 207, 183. Vernon, H. M., and Hargood-Ash, D. (1922). Proc. Roy. Soc. $B, 93,198$

Hindmarsh, Margaret E., and Macpherson, R. K. (1962). Aust. J. Sci.,

Houghten, F. C., Teague, W. W., and Miller, W. E. (1926). J. Amer. Soc. Heat. Vent. Engrs., 32, 473.

, and Yagloglou, C. P. (1923a). ibid., 29, 165. (1923b). ibid., 29, 515 .

Ingels, Margaret (1924). ibid., 30, 453.

Ionides, Margaret, Plummer, J., and Siple, P. A. (1945). Office of the Quartermaster General (U.S.), Report from Climatology and Quartermaster General (U.S.), Report from Climatology

Koch, W., Jennings, B. H., and Humphreys, C. M. (1960). A.S.H.R.A.E. Journal, 2, (No. 4), 63 .

Lee, D. H. K. (1956). Paper to the Twentieth International Physiological Congress, Brussels, 1956.

(1958). Arid Zone Research-X Climatology, Reviews of Research, p. 102. U.N.E.S.C.O. Paris.

Macpherson, R. K. (1960). Spec. Rep. Ser. med. Res. Coun. (Lond.), No. 298.

McArdle, B. and Dunham, W., Holling, H. E., Ladell, W. S. S., Scott, J. W., Thomson, M. L., Weiner, J. S. (1947). Med. Res Coun. (Lond.), R.N.P. Rep. No. 47/391.

McConnell, W. J., Houghten, F. C., and Phillips, F. M. (1923) J. Amer. Soc. Heat. Vent. Engrs, 29, 507.

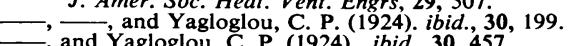

Medical Yagloglou, C. P. (1924). ibid., 30, 457.

Medical Research Council (1923). Spec. Rep. Ser. med. Res. Coun. (Lond.), No. 73.

Molnar, G. W. (1960). In Cold Injury, ed. S. M. Horvath, p. 175. Capital City Press, Montpelier.

Nelson, N., Eichna, L. W., Horvath, S. M., Shelley, W. B., and Hatch, T. F. (1947). Amer. J. Physiol., 151, 626.

Palmai, G. (1962). Med. J. Aust., I, 9.

Plummer, J. H., Ionides, Margaret, and Siple, P. A. (1945). Office of the Quartermaster General (U.S.), Report from Climatology and Environmental Protection Section, August 20, 1945.

Robinson, S., Turrell, E. S., and Gerking, S. D. (1945). Amer. J. Physiol., 143, 21 .

Shaw, W. N. (1888). Phil. Trans., 179a, 73.

Siple, P. A., and Passel, C. F. (1945). Proc. Amer. phil. Soc., 89, 177.

Smith, F. E. (1955). Memor. med. Res. Coun. (Lond.), No. 29.

Vernon, H. M. (1930). J. Physiol. (Lond.), 70, XV. (1932). J. industr. Hyg., 14, 95.

, and Warner, C. G. (1932). J. Hyg. (Lond.), 32, 431.

Webb, C. G. (1959). Brit. J. industr. Med., 16, 297.

(1960). J. Instn Heat. Vent. Engrs, 27, 297.

Wexler, A., and Brombacher, W. G. (1951). U.S. National Bureau of Standards Circular 512. 
Winer, P., Maritz, J. S., and Wyndham, C. H. (1962). Nature (Lond.), 193,848 .

Winslow, C.-E. A Gage A. P. Greenburg I Moriyama, I M. and Rodee, E. J. (1935). Amer. J. Hyg., 22, 137.

Yagloglou, C. P., and Miller, W. E. (1924). J. Amer. Soc. Heat. Vent. Herrington, L. P., and Gagge, A. P. (1936a). Amer. J. Physiol., 116, 641 . (1936b). ibid., 116, 669.

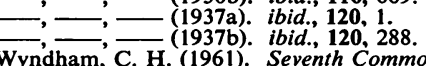

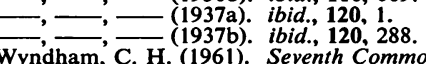
lurgical Congress.
Yagl, (1925). ibid., 31, 59.

Yaglou, C. P. (1927). ibid., 33, 285. Regulation and the Science of (1949) In Physiology of Heat Regulation and the Science of
Clothing, ed. L. H. Newburgh, p. 277. Saunders, Philadelphia.

Baetjer, Anna M., Machle, W., McConnell, W. J., Shaudy, L. A., Winslow, C.-E. A., and Witheridge, W. N. (1950). Amer. J. publ. Hlth, 40, Part II, 131.

_, and Minard, D. (1957). A.M.A. Arch. industr. Hlth, 16, 302. 